for discriminating between the spectral lines from charged and those from uncharged particles. A small condenser is placed close to the slit so that the canal rays pass between its plates, the vacuum being as high as possible so that the particles may not, after passing through the slit, become charged or uncharged through collisions. The spectrum of the light emitted by the rays is then photographed, first with the condenser short-circuited and then with the condenser charged. (Apparently the slit ordinarily employed in a spectroscope is here dispensed with, the line corresponding to each wave-length being an image of the pencil of rays itself.) Since the charged particles are deflected by the electric field, the lines due to these particles are distorted when the condenser is charged and can thus be distinguished from the lines due to uncharged particles. Photographs were shown in which certain oxygen and hydrogen lines were seen to be undistorted by the influence of the condenser, while others were clearly distorted. The latter belong to the spark spectrum of oxygen, while the former are arc lines. A similar distortion was observable with the band spectrum of nitrogen.

The foregoing considerations throw light on an apparent discrepancy between measurements of the velocity of the rays by electromagnetic methods and by the Doppler effect respectively. The velocities as measured electromagnetically increase in proportion to the square root of the accelerating potential, in accordance with theory, but the velocities as measured by the Doppler effect have been found by several observers to reach a limiting value as the accelerating potential rises beyond a certain stage. Dr. Krefft, however, raised the accelerating potential in a tube filled with hydrogen to 70,000 volts, and in this case he found no limiting value for the Doppler displace- ment; the latter indicated a velocity increasing in proportion to the square root of the potential, but its absolute value was less than what would be expected from the velocities measured electromagnetically. The arc lines of oxygen also show an unexpectedly small shift, while the spark lines show a larger shift. The discrepancy referred to may therefore be attributed to the fact that the bulk of the luminosity comes from uncharged atoms while the electromagnetic measurements relate to charged particles, which on the average have greater velocities.

A further investigation has been made by Ran, who arranged a glass cylinder close to the canal rays and with its axis perpendicular thereto. In this way light from both approaching and receding particles is collected by the cylinder and focussed on the slit of a spectroscope. Ran found some evidence for regarding the band spectrum of nitrogen as emanating from positively charged particles.

New results have been obtained by Döpel in the analysis of positive rays by Sir J. J. Thomson's method, negatively charged particles of $\mathrm{H}, \mathrm{H}_{2}, \mathrm{He}$, and $\mathrm{Ne}$ (or ? O) having been found. Most positive-ray parabolas show two regions of maximum intensity, and a new explanation is suggested for this phenomenon, namely, that the second maximum is due to particles of double mass originating in the discharge chamber but afterwards dissociated. The existence of molecules of $\mathrm{He}_{2}$ and $\mathrm{H}_{4}$ would be implied by this theory, but not $\mathrm{H}_{6}$, since there is no second maximum in the case of $\mathrm{H}_{3}$.

Prof. Wien remarked in conclusion that the work on positive rays affords an excellent example of the results of international co-operation in science, which he regards as of the utmost value and importance.

\title{
International Commission for the Investigation of the Upper Air.
}

A MEETING of the International Commission for $A$ the Investigation of the Upper Air was held in London on April I7-22.

At the meeting of the Commission in Bergen in July I92I, the Commission adopted the view that the international publication of the results of the investigation of the upper air ought to be resumed, and that an International Bureau should be established and supported by contributions from the different States, so that the preparation and compilation of the results should not in future be done at the sole cost of the National Service which undertook the work. Unfortunately, it did not prove practicable, in the stringent economic times which followed the meeting of I92I, to obtain the funds which were necessary to carry out the recommendations of the meeting at Bergen. In consequence of this, Prof. V. Bjerknes who had been president of the Commission, resigned his position, as he could not spare the time from his purely scientific work to carry out unaided the large amount of work involved in the preparation and publication of the international upper air results. Sir Napier Shaw, then President of the International Meteorological Committee, took over the presidency of the Commission at the request of the members.

Various methods for securing the object of an international publication of upper air results have been considered or tried experimentally since that time. No satisfactory solution of the question has been achieved. A short meeting of the Commission was held after the International Conference at Utrecht in 1923 at which the results of the inquiries were briefly surveyed, and a preliminary discussion took place on the most appropriate form for an international publication.

In I 924 , at the meeting of the International Union for Geodesy and Geophysics at Madrid, the Union voted the sum of 5 ool. towards the expenses of publication of a specimen volume of upper air data, and Prof. van Everdingen, the director of the Meteorological Institute of Holland, promised a contribution of about rool. for the same purpose.

The meeting of the Commission in London was concerned primarily with the consideration of the form which the specimen publication should take. Representatives from the following countries attended: France (Capt. Wehrlé) ; Germany (Prof. Hergesell); Great Britain (Sir Napier Shaw, Sir Gilbert Walker, Capt. C. J. P. Cave, Lieut.-Col. E. Gold, Mr. L. H. G. Dines, Mr. L. F. Richardson); Holland (Prof. van Everdingen, Prof. van Bemmelen); Italy (Lt.-Col. Matteuzzi, Prof. Gamba) ; Norway (Dr. Hesselberg); Russia (Dr. Molchanoff); Spain (Col. Meseguer). The meetings of the Commission were divided into business meetings and scientific meetings, on the ground that a right solution of the questions which the Commission had to consider could only be achieved by a correct appreciation of the scientific principles involved. There were four business meetings and three scientific meetings.

At the first meeting of the Commission on Friday, April 17 , the president read a letter from Mr. la Cour, director of the Danish Meteorological Service, giving the Commission the welcome news that four wireless stations would be in operation in Greenland during the coming summer, at Angmagsalik, Julianehaab, Godthaab, and Godhavn; and that all four stations would be equipped with instruments for observations of pilot balloons. The work of the four stations as regards investigation of upper wind would be coordinated by wireless with the view of obtaining simultaneous ascents to great heights from all stations at the same time.

$$
\text { NO. } 2898 \text {, VOL. I I } 5]
$$


In a communication from M. Fontséré (Barcelona) an account was given of some observations on oscillations of short period, indicated by the well-known oscillations of the motion of pilot balloons, as seen in a pilot balloon theodolite. These oscillations appear to have a period of about three seconds, and do not appear to be due to natural oscillations of the balloon. The Commission decided to recommend that a similar investigation should be undertaken in other places, and that the influence of the size and form of the balloon on the character of the oscillations should be explored, and that a comparison of the oscillations observed in balloons with those observed in the tension of kite wires should also be made.

After some discussion of the use that should be made of the funds placed at the disposal of the president, the Commission decided that they should be applied to the publication of a specimen volume of upper air results for 1923 and 1924 , and that in the specimen volume the observations obtained from ballon-sonde and similar records from the places selected for international investigation, should be published in the form of tables giving full details, and that the tables should be supplemented by graphical representation on "tephigrams." This is the name given to the representation of the results of the ballon-sonde ascents, by plotting corresponding values of temperature $t$, and entropy $\phi$, which is proportional to the logarithm of potential temperature $T$. This form of representation, which was invented by the president and explained by him at the scientific meeting, is peculiarly appropriate for presenting the results of temperature (and humidity) observations in the upper air. It shows immediately the relation of the temperature gradient observed in the ascent to the adiabatic gradient for dry air and the adiabatic gradient for saturated air. It shows the energy which would be required to raise air vertically in the atmosphere under the conditions of the ascent, or alternatively, the energy that would be set free in a kilogram of air rising in the atmosphere under the conditions of the ascent. It also has the great advantage of presenting these results in a diagram of very moderate dimensions, even when observations at heights of 50,000 feet or more are included.

Considerable discussion took place on a proposal sent by Dr. Marvin for concentrating all the international ballon-sonde ascents in any one year into a single month. The proposal to obtain ascents daily for a month in addition to ascents on single days in other months of the year, was advocated by Lieut.-Col. Gold at the meeting at Bergen in I92I, but it was rejected by the Commission on the ground that the funds available for upper air investigation should be devoted to obtaining results for detailed investigation on the lines adopted by the Norwegian Geophysical Institute. After much discussion of Dr. Marvin's proposal, it was agreed that countries participating in the international investigation of the upper air should be asked to make, so far as possible, daily ascents distributed throughout a month in each year, the month to be selected by the International Commission, these ascents to be additional to those indicated in the scheme of international days prepared by the Commission at Bergen for the years up to I928. The first month selected for this more extended investigation is May I926, and the next month is October I927. (It was considered that the time was too short to warrant an "International Month" in 1925, but it was agreed that any auxiliary ballonsonde results which any country might be able to make, should be made in August.)

In the course of discussion of this resolution, Prof. Hergesell emphasised that the international investiga- tion of the upper air has two aspects, the world aspect and the regional aspect. From the world aspect, ascents over a month would be appropriate, and from the regional aspect, ascents concentrated into shorter periods of time, and made more frequently, would lead to better results. Dr. Simpson, following up this line of thought, made the suggestion that the Commisston itself should deal only with the world aspect and should appoint regional sub-commissions to deal with regional aspects. The Commission eventually decided that the regional aspect could, in the meantime, be dealt with satisfactorily by the nomination of deputypresidents in the following different regions: Europe, with Russia, Siberia, and North Africa; North America; the East Indies and the Philippines; Australia; South Africa; South America. It was agreed that the six ascents left at the disposal of the president should be concentrated in the international months, and the exact dates in the different regions should be left to the deputy-presidents for these regions. Dr. Marvin was designated as deputy-president for North America and Mr. J. H. Field for the East Indies.

The question of adopting an international formula for the rate of ascent of balloons, put forward by Dr. Weinberg (Leningrad), led to the appointment of a sub-commission to consider this and other questions relating to balloons, and to report to the next meeting of the Commission. The members of the subcommission are: Prof. Hergesell (president), Dr. Hesselberg, Mr. J. S. Dines, Dr. Molchanoff, Col. Matteuzzi, Dr. Marvin, and Mr. Fujiwhara.

The importance of aeroplane observations, and the difficulty of securing satisfactory instruments for them, was emphasised by Capt. Wehrlé, and the Commission decided to ask for complete particulars of the instruments and methods used in different countries to be communicated, with the view of their publication in collected form by the French Meteorological Service.

As regards the future, it was decided that the question of a regular international publication could only be settled satisfactorily after the specimen volume had been issued and considered. The question of the publication of results after 1924 was, therefore, remitted to the next meeting of the Commission, which it is anticipated will be held at Prague in 1927 .

On Thursday evening, April 16, the delegates were entertained by the president at an informal "At home" at his house. Various graphical methods of presentation and illustration of upper air results were exhibited, and some interesting photographs were shown illustrating the growth and decay of vortices in a fluid in connexion with the theory which Mr. Fujiwhara has developed of the vortex motion exhibited in clouds. On Friday, April I7, the delegates were entertained to dinner by the Meteorological Office. On Sunday, April r9, they were invited by Capt. C. J. P. Cave to lunch at the Beacon Hotel at Hindhead, and afterwards to tea at Stoner Hill, Petersfield, where they had an opportunity of seeing an unrivalled collection of cloud photographs, while the rain outside witnessed to the accuracy of the Meteorological Office forecasts. On Tuesday afternoon, April 2I, they paid a visit to Kew Observatory in connexion with the seventy-fifth anniversary of the Royal Meteorological Society, and on Wednesday evening they were entertained at the anniversary dinner of the Society.

The outstanding impression left by the meeting may be illustrated by a remark to me of one of the foreign delegates: "What I like about this international work is the way everybody is ready to help things forward; the only consideration being, 'Is the thing good ?" It is very pleasant." E. GoLD.

NO. 2898 , voL. I I 5$]$ 